Motrivivência Ano XXI, No 32/33, P. 280-295 Jun-Dez./2009

\title{
"JOGAR BOLA, BRINCAR NA PRACINHA E PLANTAR BANANEIRA": representações sociais de crianças sobre a educação física
}

\author{
Deise lara Mensch? \\ Maria Simone Vione Schwengber ${ }^{2}$
}

\begin{abstract}
Resumo Abstract
O presente estudo inscreve-se no The present study enrolls itself in the campo da Educação Física Escolar. Buscamos nesta pesquisa identificar o modo como as crianças das terceiras séries do Ensino Fundamental de escolas públicas municipais e estaduais da cidade de ljuí (RS) representam a Educação Física enquanto área do conhecimento.

Nesta direção localizamos duas escolas: uma em que as aulas de Educação Física são ministradas pelo professor específico da área e field of the School's Physical Education. We aimed in this research to identify the way that the children of the third grades of Elementary School of public municipal and state schools in ljuí (RS) represent the Physical Education while field of knowledge. In this direction, we located two schools: one in which the Physical Education classes are ministered by the specific teacher of the area and another in which the classes are
\end{abstract}

1 Graduada em Educação Física pela Universidade Regional do Noroeste do Estado do Rio Grande do Sul - Unijuí. Tutora EaD do Curso de Educação Física Unijuí. Pós-graduanda em Tecnologias da Informação e Comunicação Aplicadas a Educação pela Universidade Federal de Santa Maria - UFSM. deise.mensch@unijui.edu.br

2 Doutora em Educação. Professora do Curso de Educação Física e do Mestrado em Educação nas Ciências da Universidade Regional do Noroeste do Estado do Rio grande do Sul - Unijuí. Participante do Grupo de Estudos de Educação e Relações de Gênero - Geerge, vinculado ao PPG-EDU da UFRGS e membro do grupo Paidotribus. 
Ano XXI, n 32/33, junho e dezembro/2009

outra em que são conduzidas pelo professor unidocente. Levantamos

a seguinte pergunta de pesquisa: Quais as representações sociais das crianças da terceira série do Ensino Fundamental em relação às aulas de Educação Física? Participaram da pesquisa 24 crianças, 12 de cada escola. A organização dos dados deu-se em 3 momentos: por uma dinâmica de associações de palavras; pela elaboração de um desenho com o tema "Educação Física na escola"; e as falas das crianças acerca de sua produção. Das análises que resultaram dessa investigação, constatamos que existem diferenças entre as representações das crianças sobre as aulas de Educação Física com um profissional da área e com o professor não específico, alcançandose os seguintes resultados: o grupo de crianças em que as aulas de Educação

Física são ministradas pelo professor

unidocente descreveu 32 palavras associadas a estas aulas, enquanto o grupo em que as aulas são ministradas pelo professor da área de Educação

Física relacionou 111 palavras; a tendência no $1^{\circ}$ grupo é de vincular a Educação Física aos esportes e às brincadeiras, enquanto no $2^{\circ}$ grupo as crianças destacaram uma quantidade mais ampla de elementos da cultura corporal, tais como os esportes, os jogos, as brincadeiras, as atividades rítmicas, as lutas e as ginásticas; em relação à questão de onde estaria o conducted in a single teacher education context. We raised the following research question: What are the social representations of the children of the third grade of Elementary School about the Physical Education classes? Twenty four children participated of the research, twelve of each school. The data organization happened in three moments: through a dynamic of associations of words; through the elaboration of a drawing with the theme "Physical Education at the school"; and through the speeches of the children concerning their production. From the analysis that resulted of this investigation, we could draw that there are differences between the children's representations of the classes of Physical Education with a professional of the area and with a non-specific teacher. We achieved the following results: the group of children in which the classes were ministered by the single teacher described 32 words associated to these classes, while the group in which the classes were ministered by the teacher of the Physical Education area listed 111 words; the trend on the first group is to associate the Physical Education to sports and games, while on the second group the children listed a wider quantity of elements of the corporeal culture, like sports, games, rhythmic activities, fights and gymnastics; concerning the issue of where the teacher would be during 
professor durante a aula, o $1^{\circ}$ grupo relatou que "a professora saiu" e "a professora não está", enquanto no $2^{\circ}$ grupo os relatos foram diferentes: "a professora está apitando", "a professora está auxiliando" e "a professora está chamando as crianças"; os alunos do $1^{\circ}$ grupo destacaram em seus desenhos principalmente o futebol e atividades individuais, enquanto no $2^{\circ}$ grupo apareceram o vôlei, brincadeiras, atividades com corda e a ginástica.

Palavras-chave: Educação Física; Séries iniciais; Cultura corporal. the class, the first group reported that "the teacher went out" and "the teacher is not here", while on the second group the reports were different: "the teacher is refereeing", "the teacher is helping" and "the teacher is calling the children"; the drawings of the children of the first group referred especially to football (soccer) and individual activities, while the second group mentioned also the volleyball, games, activities with ropes and gymnastics.

Key-words: Physical Education; First School Years; Corporeal Culture.

\section{Introdução à problematiza- ção da pesquisa}

Ao concebermos a temática Educação Física a relacionamos à área escolar a partir da Lei 9.394/96 da LDB $^{3}$. Com essa lei, a Educação Física situa-se como um componente curricular que organiza temas de conhecimento tais como: os jogos, os esportes, as lutas, as ginásticas, as brincadeiras e as atividades rítmicas. Configura-se, assim, a Educação Física como uma área do conhecimento que no universo da escola articula a cultura corporal de movimento.

A Educação Física escolar é uma disciplina pertencente à escola que tem por objetivo introduzir e integrar o aluno no universo da cultura corporal de movimento (BETTI, 1996). A criança tem direito a ser estimulada em seu desenvolvimento integral (no que se refere às dimensões cognitiva, psicomotora, afetiva e social), uma vez que a Educação Física nas Séries Iniciais tem um papel fundamental no que tange ao desenvolvimento motor. A Educação Física como uma prática pedagógica tem como responsabilidade, segundo Arribas (2002), articular no contexto da educação escolar três grandes eixos temáticos de intervenção (e vivência): Conhecimento do Corpo; Conhecimento e Domínio do Corpo com Objeto e no Espaço (Meio Ambiente); O Corpo e o(s) Outro(s).

3 Leis de Diretrizes e Bases da Educação Nacional. 
Ano XXI, n 32/33, junho e dezembro/2009

Várias definições ao longo da História da cultura ocidental identificam a Educação Física no contexto escolar. Então, o que comumente relaciona-se a esta área? Educação Física é bola... Educação Física é ginástica... Educação Física é saúde... Educação Física é jogo... Educação Física é esporte... Educação Física é brincadeira... Educação Física é um divertimento... Educação Física é suar... Educação Física é dança... Educação Física é musculação? Passados quatorze anos das normatizações da LDB, é possível observar o que é feito nas Séries Iniciais em busca de alguma mudança na maneira da sistematização do conhecimento (primeira e terceira séries) e dos objetivos almejados no planejamento escolar, refletindo-se na perspectiva de mudanças (ou não) da sua prática. Desse modo, lançamos a seguinte pergunta de pesquisa: Como e de que modo as crianças dão significado as aulas de Educação Física?

Sabemos que conforme a Lei 10.793, que altera o artigo $26 \S 3^{\circ}$ da LDB (Lei 9.394/96), a Educação Física faz parte do currículo inclusive nas Séries Iniciais. Se na instituição escolar existe um professor de Educação Física, ele pode assumir o componente curricular; caso isso não aconteça, a Educação Física escolar ficará a cargo do professor unidocente - no Rio Grande do Sul é um professor único a lecionar todas as disciplinas vinculadas no currículo de primeira a quarta séries.

Nesta perspectiva da formação profissional e da habilitação para trabalhar com a área da Educação Física das Séries Iniciais do Ensino Fundamental, constatou-se, nos estudos de Etchepare, Pereira e Zinn (2003) que muitos dos professores que atuam nesta área não tiveram orientação para trabalhar com a Educação Física escolar. Isso, no entanto, faz com que muitos dos professores não trabalhem com os objetos (temas de conhecimento) da Educação Física ou, quando trabaIham o componente, o fazem como forma de recreação ou atividades livres, as quais não são orientadas com objetivos escolares.

É nessa direção, então, que buscamos analisar como a Educação Física é vista pelos alunos. Observamos, assim, duas escolas: uma que possui o profissional específico da área da Educação Física ministrando as aulas nas Séries Iniciais e outra em que as aulas são proferidas pelo professor ${ }^{4}$ unidocente, com o objetivo de compreender

4 A palavra "professor" aparecerá ao longo do texto no sentido tanto no masculino quanto no feminino. 
as representações sociais ${ }^{5}$ de um grupo de crianças em relação às aulas de Educação Física.

O estudo das representações sociais ajudou-nos a investigar como os educandos da terceira série do Ensino Fundamental interpretam a aula de Educação Física. Ao discorrer sobre representações sociais em crianças, Guareschi (1995, p. 219) assevera:

(...) a criança vai estruturando as representações do mundo que a cerca. Partindo inicialmente de um estado nebuloso, ela chega a um sistema de significantes que the permite expressar desde sua autodefinição até a definição dos objetos e das situações que a rodeiam.

A representação social pode ser caracterizada como um fenômeno basicamente articulado às circunstâncias culturais. Assim, partimos dos significados elaborados pelos alunos do Ensino Fundamental e nos aproximamos das suas representações em relação às aulas de Educação Física.

\section{O universo investigado}

Os sujeitos investigados são alunos do Ensino Fundamental, mais precisamente da terceira série, sendo duas as escolas escolhidas: uma em que há o professor de Educação Física atuando nas Séries Iniciais, e outra em que as aulas são ministradas pelo professor unidocente.

O critério de seleção das escolas foi a disponibilidade das mesmas e das professoras. Assim, expostos os objetivos do estudo, e conforme a aceitação das professoras e direção, houve a seleção. As escolas escolhidas foram escolas públicas da rede Estadual de ljuí -RS para, desta forma, tentar igualar o nível de ensino entre os professores. Foram selecionadas 24 crianças, 12 de cada escola, com 9 anos em média. Optamos pela terceira série do Ensino Fundamental, pois as crianças já estão alfabetizadas e são capazes de organizar um discurso sobre o tema abordado. No corpo do trabalho as escolas serão denominadas por letras para preservar suas identidades, pois acreditamos que assim serão respeitados os sujeitos e as instituições escolares envolvidas na pesquisa.

\section{Instrumento da pesquisa}

A coleta de dados se deu por meio de observações, entrevista,

5 Entendemos por representações sociais as formas de explicações das crianças (seu próprio entendimento) em relação às informações que receberam sobre algo, neste caso a Educação Física escolar. 
Ano XXI, n 32/33, junho e dezembro/2009

dinâmica e ilustrações. A entrevista não continha um roteiro básico e os procedimentos adotados possibilitaram que os sujeitos relatassem os elementos que compunham as ilustrações e as ações dos personagens envolvidos.

A dinâmica compreendeu um dos instrumentos de pesquisa. Os alunos escreveram palavras soltas que lhes vinham à mente quando o assunto era a aula de Educação Física. Em outro momento os mesmos desenharam o que compreendiam como uma aula de Educação Física. Após, em um terceiro momento, participaram de uma conversa na qual estabeleceram significados sobre os elementos que compunham o desenho criado, bem como os papéis e funções das pessoas nele representadas e suas ações.

Exemplificando, o instrumento de pesquisa foi aplicado na seguinte ordem:

- $1^{\circ}$ momento: dinâmica das palavras, quando, em uma folha de ofício, os alunos escreveram palavras soltas que lhes vinham à mente quando o assunto era Educação Física;

- $2^{\circ}$ momento: ilustrações com o tema: "aula de Educação Física"; - $3^{\circ}$ momento: composto por uma entrevista individual após as ilustrações, utilizando as mesmas para a sequência da entrevista.

Os resultados da pesquisa que tratamos aqui foram mapeados individualmente e por escola.

\section{Escola estadual " $a$ "}

A Escola Estadual "A" não possui professor específico da área da Educação Física e acolhe cerca de 290 alunos, com 7 funcionários e 28 professores. A escola atende um público variado oriundo de diversos bairros e a população é caracterizada na maioria como de classe média/baixa.

\section{Análise da escola "a": profes- sor unidocente}

Segue aqui alguns registros dos alunos sobre as representações da Educação Física na Escola: 
Figura 1: Dinâmica das palavras soltas

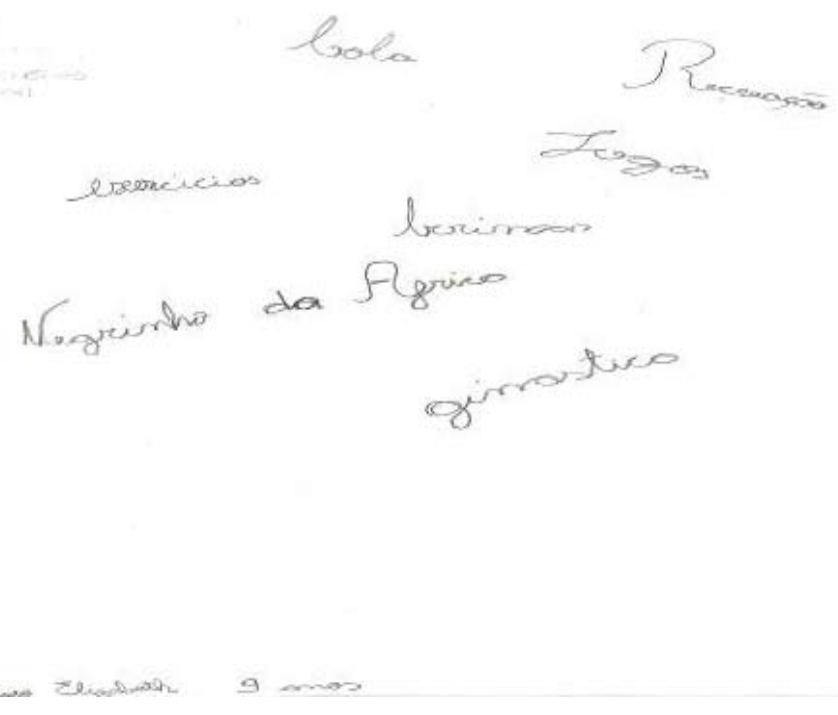

Figura 2: Ilustração e descrição das falas

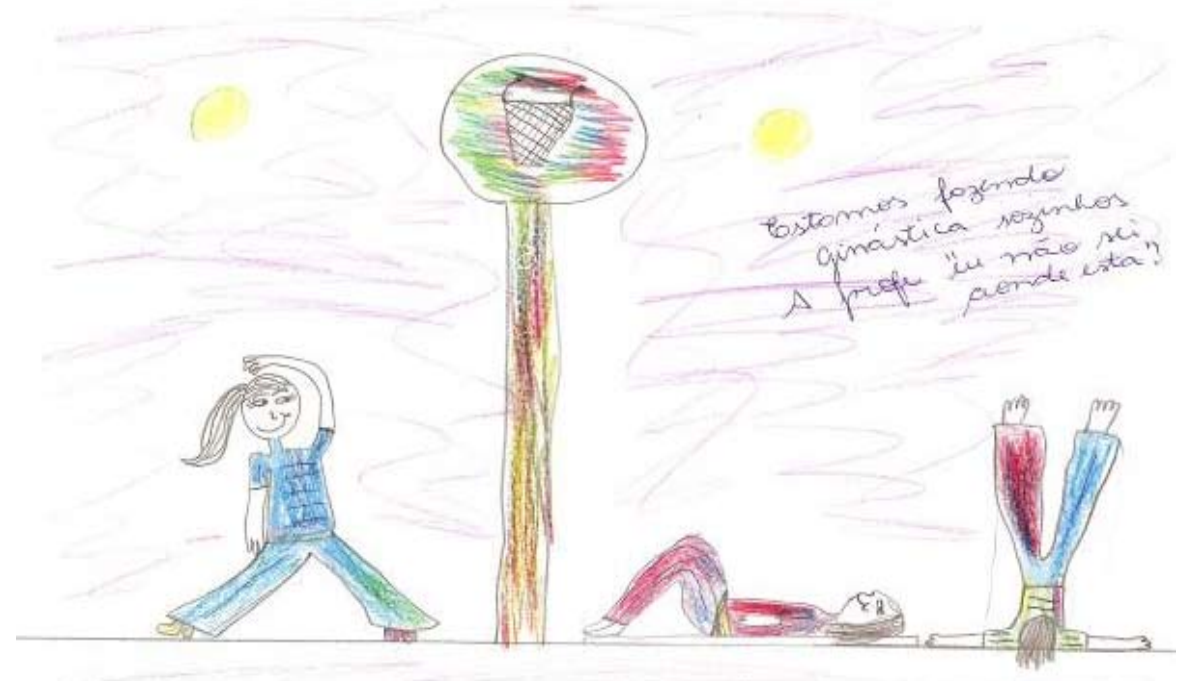


Ano XXI, n 32/33, junho e dezembro/2009

Figura 3: Ilustração e descrição das falas

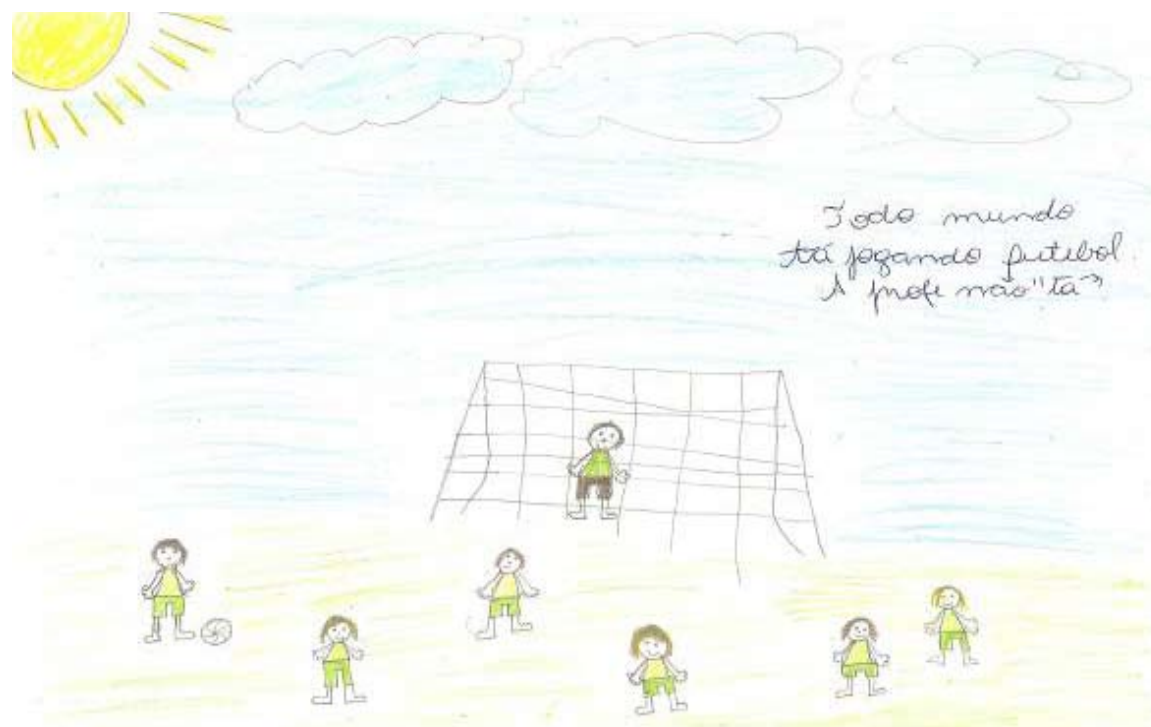

Assim, transpomos os da- aulas, aspectos pedagógicos e didos da Escola "A" para dar melhor dáticos, conforme registra a tabela visibilidade categorizando em: os conteúdos, recursos presentes nas a seguir:

\begin{tabular}{l|l|l}
\hline \multicolumn{1}{c|}{ Categoria } & Subcategorias & \multicolumn{1}{c}{ Palavras associadas } \\
\hline \multirow{2}{*}{ Conteúdos } & $\begin{array}{l}\text { Relativos aos } \\
\text { esportes }\end{array}$ & Handebol, atletismo, futebol, vôlei, basquete \\
\cline { 2 - 3 } & $\begin{array}{l}\text { Outros } \\
\text { conteúdos }\end{array}$ & $\begin{array}{l}\text { Jogos: Caçador, jogar bola. } \\
\text { Ginásticas: nenhum. } \\
\text { Brincadeiras: amarelinha, pular corda, ovo- } \\
\text { choco, negrinhos da áfrica, esconde-esconde, } \\
\text { pega-pega, roda cutia, sapata. } \\
\text { Atividades rítmicas: nenhum. }\end{array}$ \\
\hline $\begin{array}{l}\text { Recursos } \\
\text { materiais da aula }\end{array}$ & Bola, corda, carrinho. \\
\hline
\end{tabular}




\begin{tabular}{|c|c|c|}
\hline Categoria & Subcategorias & Palavras associadas \\
\hline $\begin{array}{l}\text { Aspectos } \\
\text { resultantes da } \\
\text { participação nas } \\
\text { aulas de Educação } \\
\text { Física }\end{array}$ & & $\begin{array}{l}\text { Exercícios; recreação, brincar, } \\
\text { pracinha, brincadeiras, alongamento, } \\
\text { aquecimento, torneio, ginástica. }\end{array}$ \\
\hline $\begin{array}{l}\text { Aspectos } \\
\text { pedagógicos e } \\
\text { didáticos } \\
\end{array}$ & & \\
\hline \multirow[t]{4}{*}{ Desenho } & $\begin{array}{l}\text { Práticas } \\
\text { esportivas: }\end{array}$ & Corrida; futebol \\
\hline & Outros: & Ginástica \\
\hline & $\begin{array}{l}\text { Presença do } \\
\text { professor }\end{array}$ & Nenhum \\
\hline & $\begin{array}{l}\text { Ausência do } \\
\text { professor }\end{array}$ & $\begin{array}{l}\text { A professora "saiu"; a professora não } \\
\text { "está"; "a professora não está fazendo } \\
\text { nada". }\end{array}$ \\
\hline Total: 12 alunos & & \\
\hline
\end{tabular}

As crianças desta escola demonstram na dinâmica das palavras soltas, quando solicitadas a citarem termos associados ao tema Educação Física na escola, um pequeno repertório de expressões, sendo um total de 32 , as quais lembravam o assunto em questão; 9 se relacionavam com os esportes e jogos; 23 se referiam às brincadeiras/outros e nenhuma palavra foi relacionada às atividades rítmicas e às ginásticas.

Analisando as palavras associadas à Educação Física Escolar, verifica-se que a tendência das crianças é relacionar a área da Educação Física aos "esportes" e às "brincadeiras". Podemos dizer que estes dois temas constituem o eixo central das representações sociais desse grupo de alunos. Este aspecto foi constatado pela frequência de palavras ligadas aos esportes e às brincadeiras. Sabemos que a influência histórica dos esportes tende a ser um dos fatores contribuintes para a relação Educação Física X esportes, e ainda, talvez, o excesso de palavras associadas às brincadeiras possuam uma relação próxima até pela formação dos professores em Pedagogia.

Outro elemento nomeado, relacionado à Educação Físi- 
Ano XXI, n 32/33, junho e dezembro/2009

ca, foi "pracinha". Normalmente é utilizada na aula de Educação Física como "tempo livre", na qual não existe um trabalho orientado pelo professor e, assim, as crianças brincam livremente. Deste modo, verifica-se alguns exemplos nas descrições das crianças quando perguntadas a respeito de onde estaria a professora na condução da aula. Elas relataram: "a professora saiu"; "a professora não está".

As crianças destacaram em suas representações pictórias, em maior número, o jogo de futebol. O que caracterizou estes desenhos foram as poucas crianças participando ali representadas. Neles ficam evidentes as atividades na aula de Educação Física com uma ou, no máximo, duas crianças participando. Apenas uma criança desenhou mais colegas tomando parte da aula. $\mathrm{O}$ outro elemento que apareceu foi a ginástica: a aluna desenhou somente um participante na aula. Parece-nos que, para estas crianças, as aulas de Educação Física são individualizadas, não relacionando a área com o coletivo. Entre os elementos desenhados representando o espaço físico da aula, apareceu apenas a quadra aberta das escolas.

\section{Escola municipal "b"}

A Escola Municipal "B" possui professor de Educação Física que atua nas Séries Iniciais. O professor selecionou 12 alunos aos quais aplicamos o instrumento de pesquisa. Os alunos foram bem atenciosos e realizaram as atividades com vontade. A escola é caracterizada por estar localizada próxima ao centro, atendendo a 800 alunos, possuindo 11 funcionários e 54 professores. A população tem como maior característica pertencer à classe média/baixa.

\section{Análise da escola "b": profes- sor de educação física}

A seguir alguns registros dos alunos sobre as representações da Educação Física na Escola: 
Figura 4: Dinâmica das palavras soltas

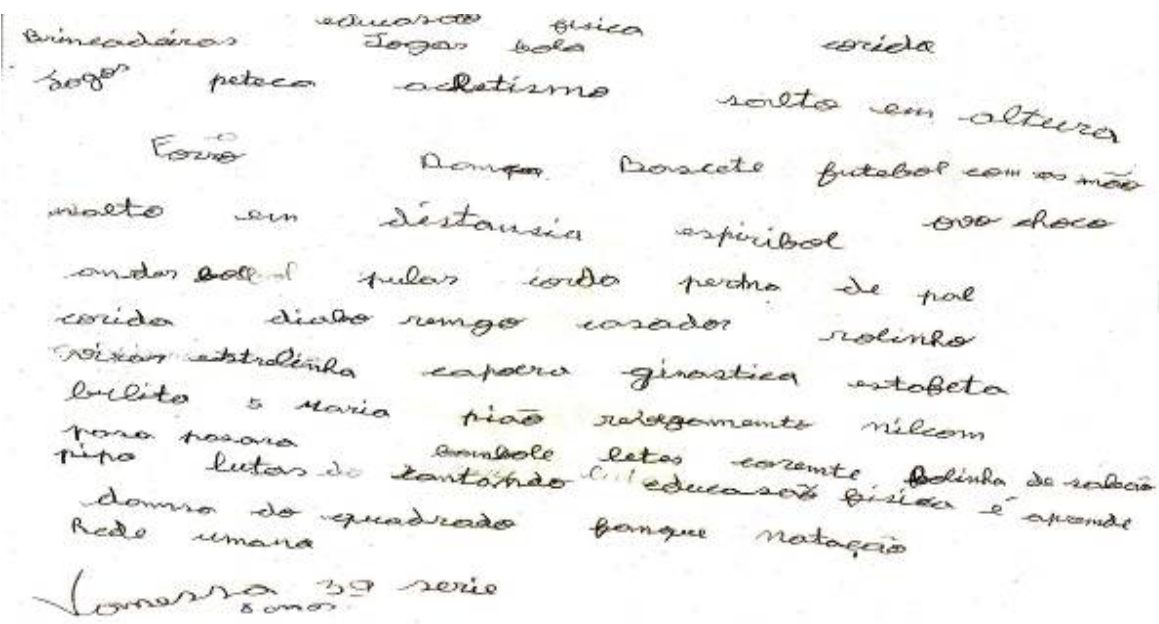

Figura 5: Ilustração e descrição das falas

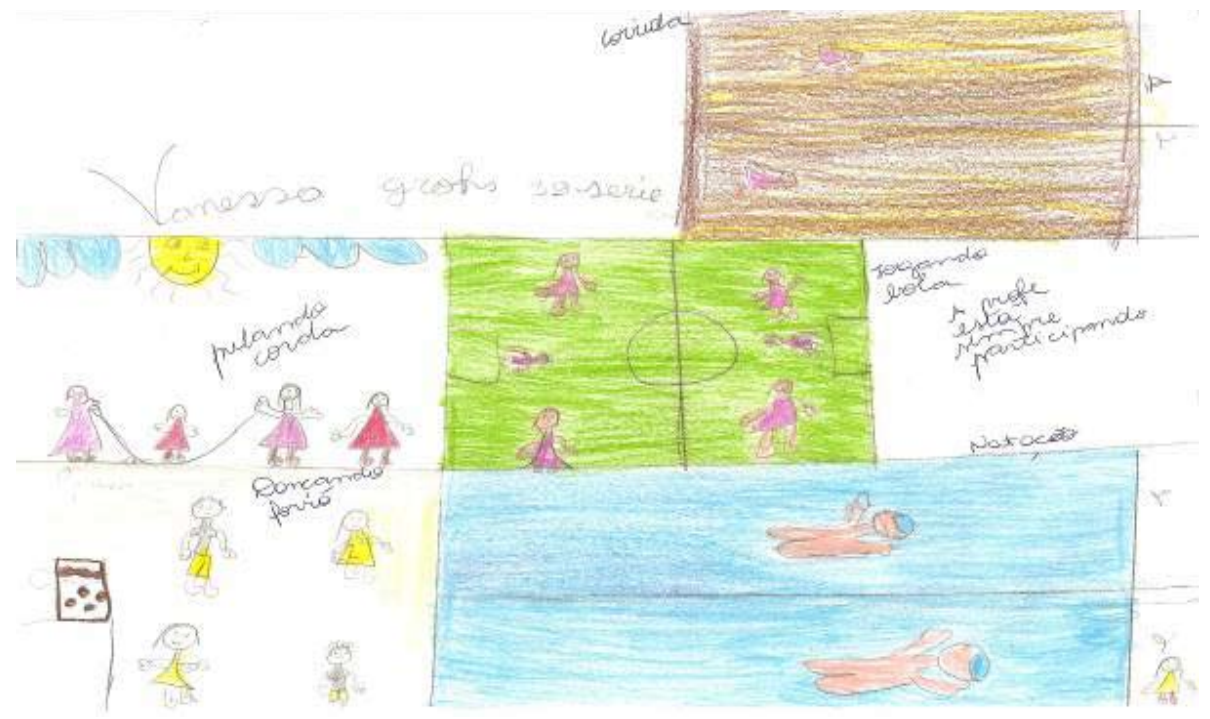


Ano XXI, n 32/33, junho e dezembro/2009

Figura 6: Dinâmica das palavras soltas

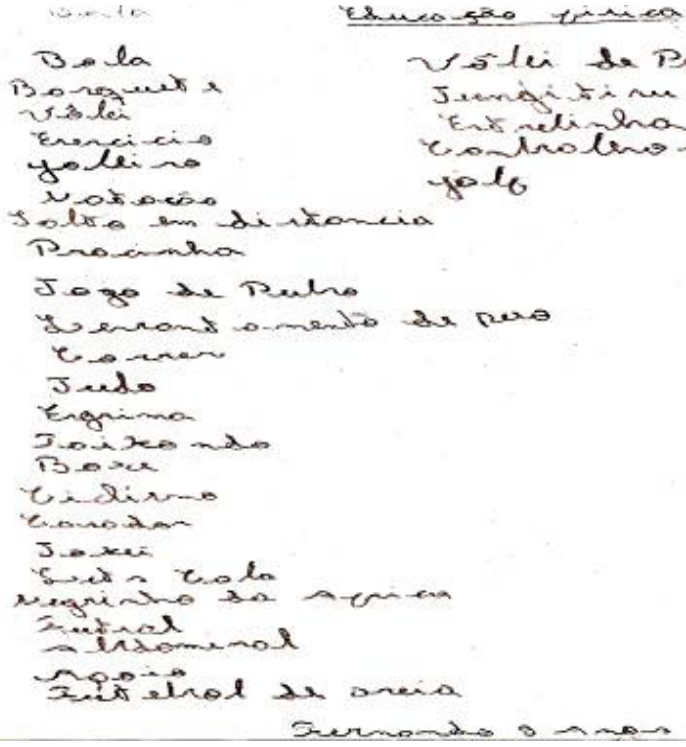

Figura 7: Ilustração e descrição das falas 
Na sequência apresentamos os dados da Escola " $\mathrm{B}$ " dispostos na Tabela:

\begin{tabular}{|c|c|c|}
\hline Categoria & Subcategorias & Palavras associadas \\
\hline \multirow[b]{2}{*}{ Conteúdos } & $\begin{array}{l}\text { Relativos aos } \\
\text { esportes }\end{array}$ & $\begin{array}{l}\text { Vôlei, futebol, atletismo, } \\
\text { basquete, natação, futsal, } \\
\text { handebol, tênis, ciclismo, } \\
\text { halterofilismo, futsal, } \\
\text { fresbee, tênis de mesa. }\end{array}$ \\
\hline & $\begin{array}{l}\text { Outros } \\
\text { conteúdos }\end{array}$ & $\begin{array}{l}\text { Jogos: Espiribol, } 10 \\
\text { passes (pré-desportivo ao } \\
\text { handebol), caçador, nilcon } \\
\text { (pré-desportivo ao vôlei), } \\
\text { atividades com bola, rede } \\
\text { humana (pré-desportivo ao } \\
\text { vôlei), caçador, futebol com } \\
\text { as mãos, estafeta. } \\
\text { Lutas: luta, luta do jacaré, } \\
\text { capoeira, karatê, judô, tae } \\
\text { kwon do, jiu-jítsu, esgrima, } \\
\text { boxe. } \\
\text { Brincadeiras: Lets, pular } \\
\text { corda, perna de pau, corrida } \\
\text { do saco, } 5 \text { marias, pular } \\
\text { corda, pega-pega, diabo- } \\
\text { rengo, bolinha de sabão, } \\
\text { passa-passará, esconde- } \\
\text { esconde, ovo-choco, lets } \\
\text { cola, negrinhos da áfrica. } \\
\text { Atividades rítmicas: funk, } \\
\text { hip - hop, canto, dança, } \\
\text { forró, quadrilha. } \\
\text { Ginásticas: rolinho, } \\
\text { estrelinha, carrinho de mão, } \\
\text { ponte, salto mortal, parada } \\
\text { de mão, ginástica, ginástica } \\
\text { artística. }\end{array}$ \\
\hline $\begin{array}{l}\text { Recursos materiais } \\
\text { da aula }\end{array}$ & & $\begin{array}{l}\text { pipa, peteca, bambolê, } \\
\text { corda, tema de casa, bolita, } \\
\text { perna de pau, trabalhos, } \\
\text { pesquisa, bola, boliche, } \\
\text { pião, bola, quadra, apito. }\end{array}$ \\
\hline
\end{tabular}


Ano XXI, n 32/33, junho e dezembro/2009

\begin{tabular}{|c|c|c|}
\hline $\begin{array}{l}\text { Aspectos } \\
\text { resultantes da } \\
\text { participação nas } \\
\text { aulas de Educação } \\
\text { Física }\end{array}$ & & $\begin{array}{l}\text { Alongamento, aquecimento, } \\
\text { exercícios, pracinha, } \\
\text { abdominal, apoio, polichinelo, } \\
\text { musculação, goleiro, torneio, } \\
\text { pênalti, brincar. }\end{array}$ \\
\hline $\begin{array}{l}\text { Aspectos } \\
\text { pedagógicos e } \\
\text { didáticos }\end{array}$ & & Aprendizagem, é aprender. \\
\hline \multirow[t]{4}{*}{ Desenho } & $\begin{array}{l}\text { Práticas } \\
\text { esportivas: }\end{array}$ & $\begin{array}{l}\text { Basquete, atletismo, } \\
\text { espiribol, vôlei, natação, } \\
\text { futebol. }\end{array}$ \\
\hline & Outros: & $\begin{array}{l}\text { Pulando corda, dançando, } \\
\text { brincadeira do elástico. }\end{array}$ \\
\hline & $\begin{array}{l}\text { Presença do } \\
\text { professor }\end{array}$ & $\begin{array}{l}\text { Apitando, auxiliando, } \\
\text { participando da atividade, } \\
\text { organizando as atividades, } \\
\text { chamando as crianças, a } \\
\text { professora sempre participa, } \\
\text { olhando as meninas tirando } \\
\text { foto após o campeonato. }\end{array}$ \\
\hline & $\begin{array}{l}\text { Ausência do } \\
\text { professor }\end{array}$ & $\begin{array}{l}\text { "A professora não está } \\
\text { fazendo nada"; "foi no } \\
\text { banheiro". }\end{array}$ \\
\hline
\end{tabular}

Total: 12

alunos

\section{Análise da escola "b"}

Podemos visualizar que o grupo de alunos que tem as aulas de Educação Física ministradas por um professor específico da área, descreveu 111 palavras; destas, 30 corresponderam às atividades relacionadas aos esportes e jogos; 32 se referiram às atividades rítmicas e às ginásticas e, ainda, 49 palavras estavam entre as brincadeiras e outros.
Os alunos possuem um leque mais amplo no seu repertório ao se expressarem sobre Educação Física. Este aspecto foi constatado pela frequência de palavras associadas aos temas relacionados na representação social das aulas de Educação Física. Podemos destacar que estes alunos nomeiam os conhecimentos desenvolvidos como os esportes, os jogos, as lutas, as brincadeiras, as ginásticas e as atividades rítmicas. 
Observamos a presença do professor de Educação Física em ações como "apitando", "auxiliando", "orientando as crianças". Notamos que em algumas ilustrações os alunos representam uma sequência de atividades, separadas em cenas. Isso indica uma tentativa em demarcar o espaço e o tempo das ações pedagógicas vivenciadas. Em muitos dos desenhos apareceram recursos, como a quadra da escola e muitos materiais pertencentes às aulas de Educação Física como: bolas, rede de voleibol, corda, bastão de revezamento. Os esportes destacados foram o futebol, a natação, a corrida de revezamento, o voleibol e o espiribol.

$$
* * *
$$

Lamentavelmente, muitas Secretarias de Educação no Brasil consideram desnecessária a presença de professores da área da Educação Física para orientação da prática de atividades físicas com crianças pré-escolares e dos primeiros ciclos. Por conseguinte, muitas vezes há descaso com o componente curricular,

A pesquisa em questão mostra que o professor unidocente prioriza mais as brincadeiras de forma livre e menos um trabalho sistematizado. Acreditamos que é necessária, uma formação bastante consistente e ampla nos cursos de Magistério e nos superiores de Pedagogia e de Educação Física, a fim de que os professores compreendam o compromisso (objeto) da área da Educação Física no desenvolvimento do aluno.

\section{REFERÊNCIAS}

ARRIBAS, Tereza Lleixa. A Educação Física de 3 a 8 anos. Porto Alegre: Artmed, 2002.

BETTI, Mauro. A janela de vidro: esporte, televisão e Educação Física. São Paulo: Papirus, 1996.

BETTI, Mauro; PIRES, Giovani De Lorenzi. Mídia. In: GONZÁLES, Fernando Jaime; FENTERSEIFER, Paulo Evaldo (Orgs). Dicionário Crítico de Educação Física. ljuí: Ed. Unijuí, 2005. p. 282- 288. BRASIL. Lei $\mathrm{n}^{\circ} 10.793$, de $1^{\circ}$ de dezembro de 2003. Altera a redação do art. $26 \S 3$ e o art. 92 da lei 9.394 de 20 de dezembro de 1996, que "estabelece as diretrizes e bases da educação nacional" e dá outras providências.

BRASIL. Parecer CNE/CEB 16, de 3 de julho de 2001. Diário Oficial da União. Brasília, DF, 3 de dezembro de 2001. Disponível em: < http://portal.mec.gov.br/ 
Ano XXI, n 32/33, junho e dezembro/2009

cne/arquivos/pdf/ pceb16_01. pdf > . Acesso em: Ago $200 \overline{8}$.

CANFIELD, M. S. A Educação Física nas Séries Iniciais: paralelo entre 15 anos. Kinesis, Santa Maria, n. 23, p. 87-102, 2000.

DIRETRIZESEBASESDAEDUCAÇÃO NACIONAL. Governo do Estado de São Paulo, Lei 9.394, Editora do Brasil, 1998.

ETCHEPARE, L. S.; PEREIRA, E. F.; ZINN J. L. Educação Física nas séries iniciais do Ensino Fundamental. Revista da Educação Física/UEM, Maringá, v. 14, n. 1, p. 59-66, 2003.

FREIRE, Paulo. Educação como prática da liberdade. 26. ed. Rio de Janeiro: Paz e Terra, 2002. GUARESCHI, Neuza Maria Fátima.

A criança e a representação social de poder e autoridade: negação da infância e afirmação da vida adulta. In: SPINK, Mary Jane (Org.). O conhecimento no cotidiano: as representações sociais na perspectiva da Psicologia social. São Paulo: Brasiliense, 1995. p. 212-233. MOLINA, Rosane Maria Kreusburg; MOLINA NETO, Vicente. Educação Física e educação: o espaço pedagógico para localizar a Educação Física e os fundamentos que podem mantê-la na escola. Reflexões sobre algumas possibilidades. In: CAPARRÓZ, Francisco Eduardo; ANDRADE FILHO, Nelson Figueiredo de (Orgs.). Educação Física escolar: política, investigação e intervenção. Vitória: Ufes, 2004. p. 13- 33.

NETO, C. A motricidade como expressão do desenvolvimento da criança: algumas notas históricas e pedagógicas. Livro anual da Sociedade Internacional para Estudos da Criança. Florianópolis: Udesc, 2001.

SILVEIRA, Plínio Souza. A legitimidade da Educação Física em Jataí-Goiás. 1999. Monografia (Licenciatura em Educação Física, Curso de Educação Física) Universidade Federal de Goiás, Campus Avançado de Jataí, Jataí (GO), 1999.

SOARES, Carmen L. et al. Metodologia do ensino de Educação Física. São Paulo: Cortez, 1992.

Recebido: Maio/2010 Aprovado: Agosto/2010 